Design of High-Power Ratio-Frequency

Drice Loops for Operation into 425-MHz

Linear Accelerators

D. Liskn

LA- -11265-MS

L. Dauelsberg

DE88 010305 


\title{
DESIGN OF HIGH-POWER RADIO-FREQUENCY \\ DRIVE LOOPS FOR OPERATION INTO 425-MHZ \\ LINEAR ACCELERATORS*
}

by

\author{
D. Liska and L. Dauelsberg
}

\begin{abstract}
Recent designs for ultra high-frequency (UHF) band accelerators have prompted the need for high-powered drive loops compatible with the peak and average power needs of the accelerator tanks. Two such loops have been developed in the Accelerator Technology (AT) Division at Los Alamos and are now part of the general accelerator inventory. One loop is of small size, appropriate for radio-frequency quadrupole ( $R F Q$ ) injector-accelerators, and is rated at $500-\mathrm{kW}$ peak, 2 -ms pulse length and $5 \%$ duty factor. The other loop is a 1-MW design, physically larger, also rated at 2-ms pulse length and 5\% duty factor. The 1-MW drive loop uses a flat-disk ceramic window. The 500-kW loop as developed can use either a flatdisk window or a special $\mathrm{N} / 2$ window module available from Oak Ridge National Laboratory (ORNL).

The purpose of this note is to describe the design of these loops and the tests performed on them so that they might be used by design engineers with appropriate applications.
\end{abstract}

\section{INTRODUCTION}

Low-frequency drift-tube linacs such as the 201.25-MHz section of LAMPF* and the 80-MHz tanks in FMIT** have been coupled to triode or tetrode high-power amplifiers by rf drive loops. High-frequency accelerator sections (such as the LAMPF side-coupled linac that operates at $805 \mathrm{MHz}$ ) are driven by high-frequency klystrons and coupled by means of waveguides and irises. An interesting new class of accelerators is being developed at Los Alamos that operates at $425 \mathrm{MHz}$, the center frequency of the military radar klystron. At this frequency, waveguides are still possible, but these are very bulky; the more compact drive loops are another alternative. New continuous duty accelerators are in existence at CERN and are also being developed in AT Division.

\footnotetext{
*Los Alamos Meson Physics Facility, an 800-MeV, 10-mA pulsed proton linac, operational.

**Fusion Materials Irradiation Test Facility, a 35-MeV, 100-mA CW deuteron linac, prototype only.
} 
In response to these needs, a pair of intermediate-frequency, high-powered drive loops have been developed and tested. They were designed to match commercially available coaxial transmission lines and to operate at modular power levels of $500 \mathrm{~kW}$ and $1 \mathrm{MW}$. These two units are shown in Figs. 1 and 2. The small unit is designed to power the RFQ linac with a peak power capacity of $500 \mathrm{~kW}$. The RFQ at $425 \mathrm{MHz}$ is physically small so this drive loop is restricted to $4.1-\mathrm{cm}$ diameter but is tapered up to $3^{1 / 3-i n}$. commercial size for connection to a standard coaxial driveline. The second unit that was developed matches a $6^{1 / 8-i n}$. commercial coax but is also tapered so the drive loop itself is only $9.5-\mathrm{cm}$ diameter. This larger design is configured to match a typical drift-tube linac (DTL) tank that, at $425 \mathrm{MHz}$, has a diameter of typically $42 \mathrm{~cm}$. This loop is capable of 1-MW peak.

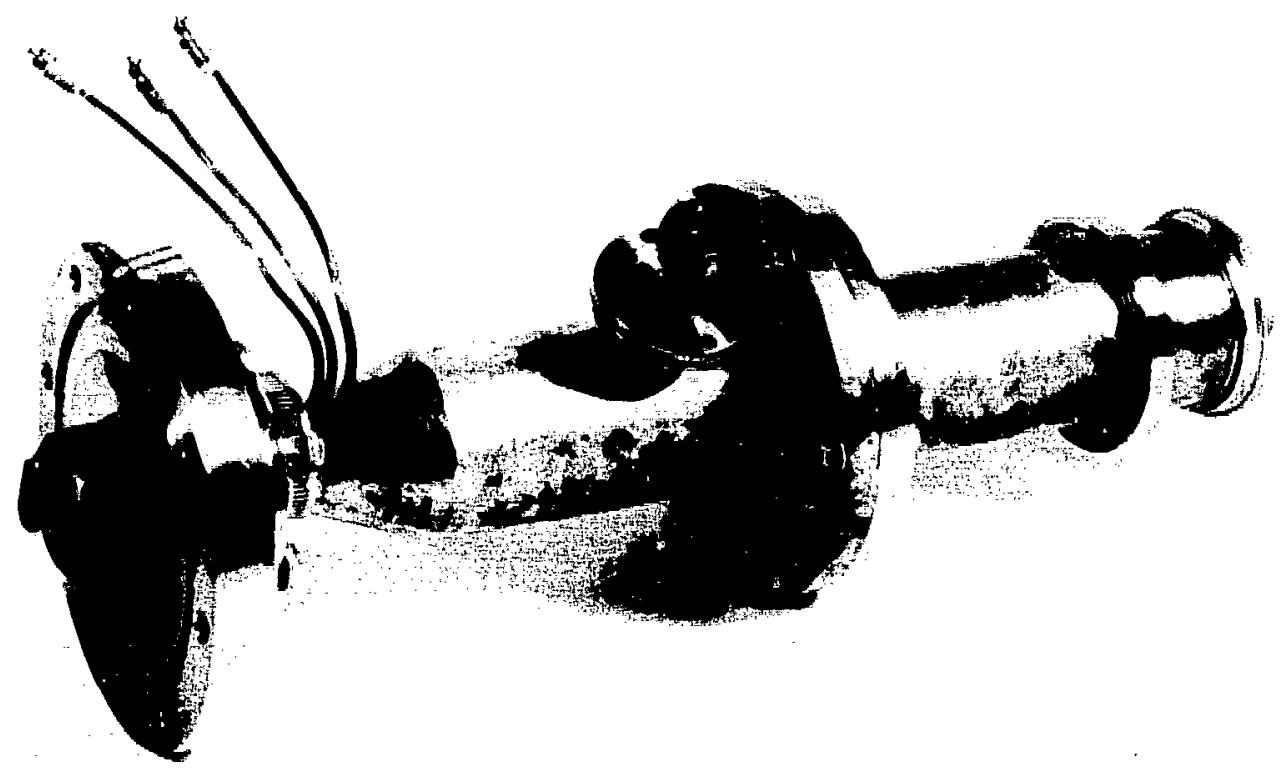

Fig. 1 The $3^{1 / 8-i n . ~} 425 \mathrm{MW}, 500 \mathrm{~kW}$, rf drive loop.

Both loops are designed for $5 \%$ duty factor, but because they are constructed of copper, they can easily be cooled to operate at much higher duty factor, possibly $\mathrm{CW}$. Tests have been performed on these loops only at low duty factor because of limitations in available capacitor banks, klystrons, and resonant test cavities, rather than inherent limitations in the loops themselves. 


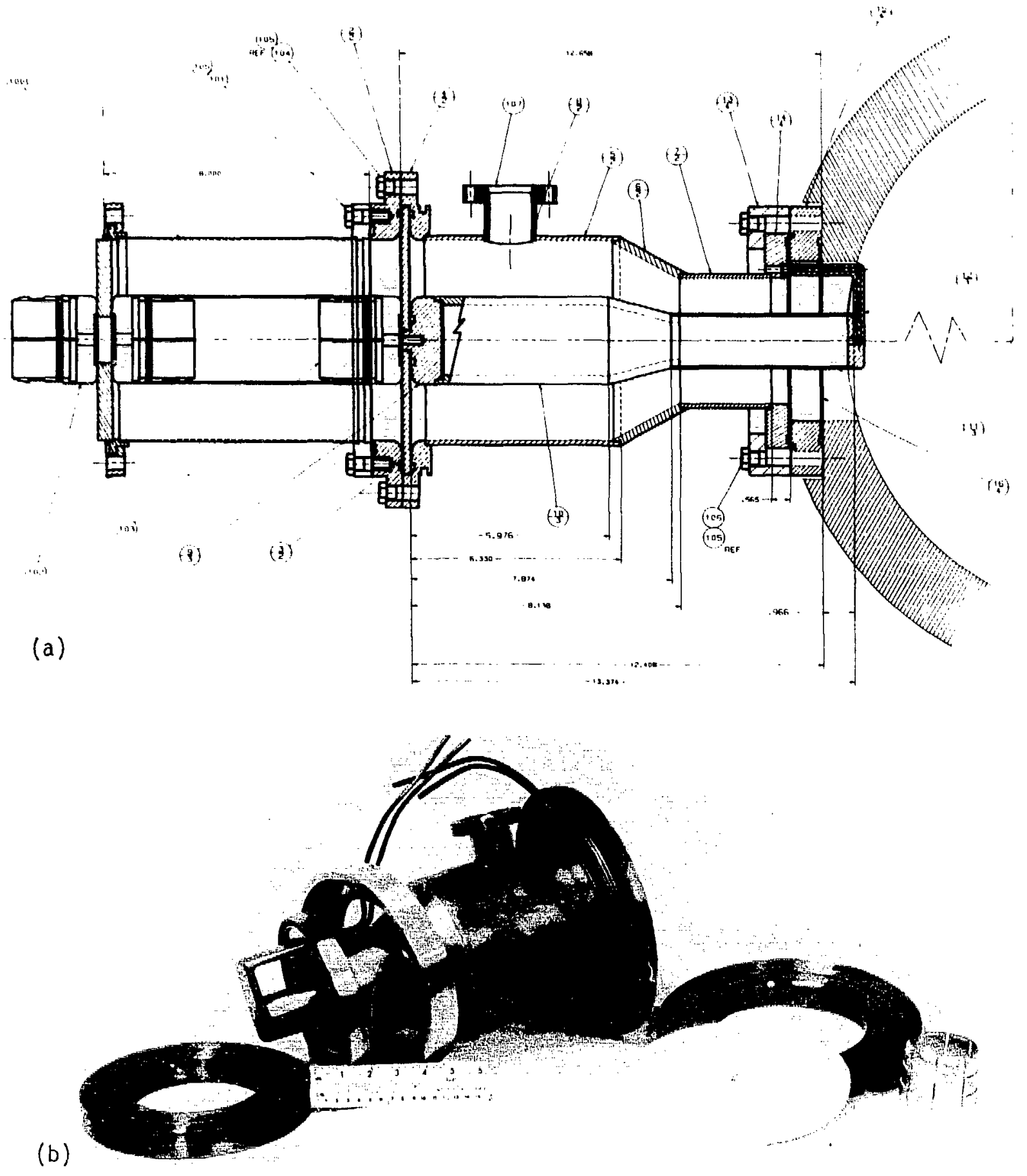

Fig. 2. The 61/8-in., $425 \mathrm{MHz}, 1 \mathrm{MW}$, rf drive locp. (a) Mechanical design features; (b.) Hardware elements. 


\section{DESIGN FEATURES}

Both drive loops are designed to operate nominally at $425 \mathrm{MHz}$. The window surfaces are located $32.73 \mathrm{~cm}$ back from the inner flat surface of the loop (one-half wavelength at $425 \mathrm{MHz}=35.27 \mathrm{~cm}$ ). This dimension is chosen from previous test experience and is not overly critical. The flat straps are designed for low inductance, about $20 \mathrm{nH}$, to provide an inductive impedance approximately equal to the $50-\Omega$ transmission line characteristic impedance at $425 \mathrm{MHz}$. The loops are designed for $50-\Omega$ impedance along their entire length in accordance with the following formula:

$$
Z_{0}=60 \ln \frac{b}{a}
$$

where $\mathrm{Z}_{0}=$ coaxial characteristic impedance, ohms

$\mathrm{b}=$ ID of outer conductor

$\mathrm{a}=\mathrm{OD}$ of inner conductor

For $\mathrm{Z}_{0}=50 \Omega$, the ratio $\mathrm{b} / \mathrm{a}=2.3$. The tapered sections of the loops are computer designed to give a constant $50-\Omega$ impedance in the frequency range close to $425 \mathrm{MHz}$. It is not as wide-band a taper as an ogee curve would give, but it is adequate for the 350 - to $500-\mathrm{MHz}$ range over which these loops can be expected to perform adequately.

The windows are flat disks and made of high-purity alumina (Coors AD 995). While the dielectric constant of this material is high $(\varepsilon=9.4)$, the dissipation factor is low; the dielectric loss tangent is acceptable to provide a proper impedance match across the window. The conductor diameter ratio is calculated as follows:

$$
\frac{b^{\prime}}{a^{\prime}}=\left(\frac{b}{a}\right)^{\sqrt{\varepsilon}}
$$

where $b^{\prime}=$ ID of outer conductor at window,

and

$$
a^{\prime}=O D \text { of inner conductor at window, }
$$

which reduces to straight conductors in air or vacuum $(\varepsilon=1.0)$. Because $\varepsilon=9.4$ for AD995 alumina, the conductor cuts must be made quite deep. These cuts are balanced at the inner and outer conductors in accordance with the following formulas:

$$
\begin{aligned}
b^{\prime} & =\frac{a+b}{1+(a / b)^{\sqrt{\varepsilon}}} \\
a^{\prime} & =\frac{a+b}{1+(b / a)^{\sqrt{\varepsilon}}}
\end{aligned}
$$

The drive loops are constructed entirely of copper; critical areas such as the window flanges, straps, and inner conductors on the vacuum side are water cooled for high average-power operation. 
Prior to operation, the metallic surfaces on the vacuum side of the window are treated with titanium nitride (TiN) to a thickness of about $20 \mathrm{~nm}$ (see Appendix). The treatment procedure uses a hot, current-carrying titanium-alloy wire (75\% tantalum, $25 \%$ titanium) in a nitrogen-rich atmosphere. ${ }^{1}$ To assure a high probability of nitride formation, an ammonia atmosphere $\left(\mathrm{NH}_{3}\right)$ at a pressure of about 1- $\mu \mathrm{m}$ is used, while the thickness of the nitride coating is monitored by observing surface resistance on a glass slide in the same cavity. The TiN surface layer has good properties, cannot be easily scrubbed off, and leaves a slight golden color on the surfaces treated.

\section{TEST APPARATUS}

\section{A. Window Test Modules}

Because satisfactory operation of a high-power drive loop is critically affected by the performance of the window, the first tests done were window tests into a "flat" (i.e., nonreflective) load, matched to the characteristic impedance of the drive line, namely $50 \Omega$. Special window test modules were fabricated for these tests (Figs. 3 and 4). The test modules were equipped with two ports, one for vacuum pump out and one for viewing the window under test. During operation, multipactoring discharges in the vicinity of the window could be picked up with phototube detectors at light levels undetectable to the unaided eye.

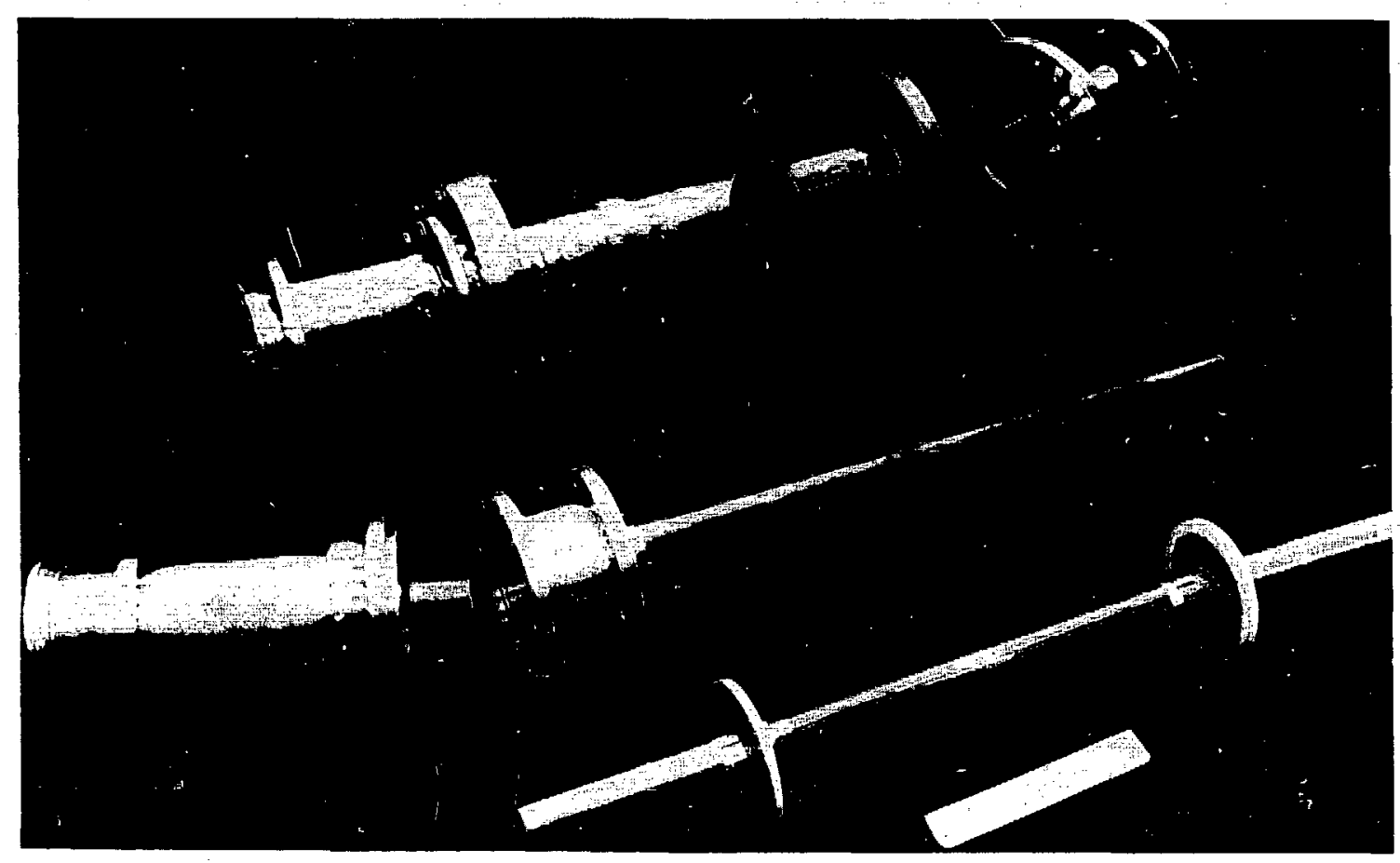

Fig. 3. The $3^{1 / 8-i n}$. window test module and rf windows. 


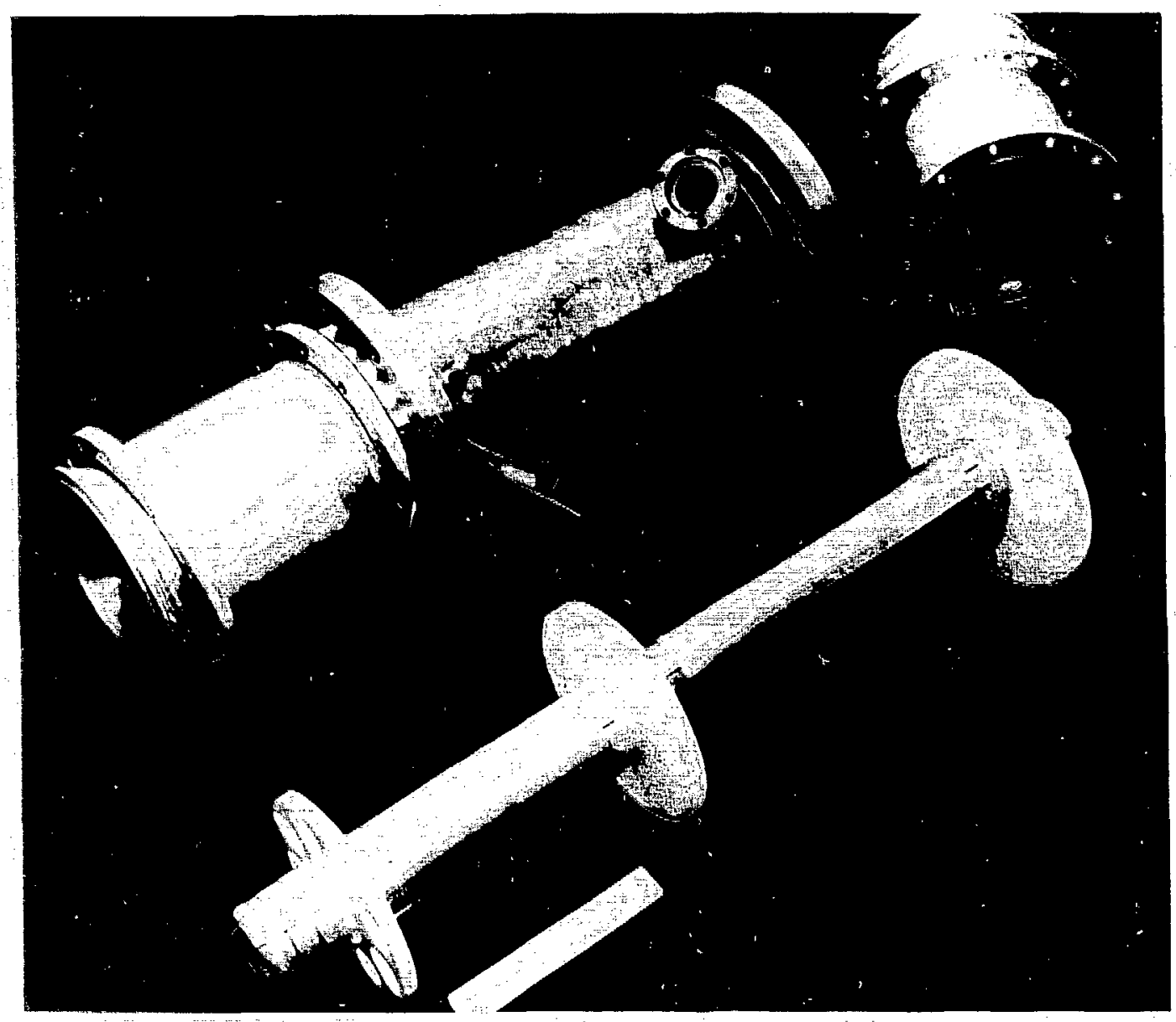

Fig. 4. The $6^{1 / 8-i n}$. window test module and $\mathrm{rf}$ windows.

The $3^{1 / 8}$-in. windows are shown in Fig. 3. The flange points located at either end of the window test module are separated by one-half wavelength. The flat-disk windows ground from high-purity alumina (Coors $\mathrm{AD} 995$ ) are positioned at these flanges. Alternately, one disk window can be removed and a window module developed by Oak Ridge National Laboratory (ORNL) can be installed instead. In either case, the volume between windows is pumped to hard vacuum, $10^{-6}$ torr or better. The Oak Ridge window module shown in Fig. 3 consists of two flat-disk windows spaced one-half wavelength apart and swaged into the inner and outer conductors so as to be vacuum tight. Because of the $1 / 2$ design, the conductors do not require impedance-matching steps as do the conductors used with the single, flat disk windows. This reduces electric field stresses on the ceramic and, furthermore, produces a very "flat," i.e., well-matched, transmission line through the window region. Although both types of windows (flat disk and ORNL) have exceeded design power expectations, as shown by test results to be discussed later, the ORNL design is preferred for this application because of its inherently greater safety margin.

In Fig. 4, a similar vacuum module is shown for the $61 / 8$-in. size power coax. The two windows' vacuum surfaces are again positioned $1 / 2$ apart, and both vacuum pump out and diagnostic view ports are again provided. Two different flat disk windows were 
tested in this case: a 0.635 -cm-thick AD 995 ceramic and a rexolite window. Rexolite is a tough rf plastic with low loss tangent and $\varepsilon=2.5$. The depths of the conductor recesses are considerably reduced because of the lower dielectric constant. Rexolite is considered a less durable back-up material in the event that unforeseen ceramic failures occur because it is cheap and easy to machine. It is used in the LAMPF 201.25-MHz drive loops and periodically changed out during routine maintenance.

All window tests were conducted into $50-\Omega$ nonreflective loads as shown in Fig. 5. An adjustable power splitter permitted uniform distribution of power into the four commercial water loads. Directional couplers were mounted at both ends of the test module to monitor forward and reflected power. The experimental circuit for the $61 / 8$-in. window tests is shown in Fig. 6. The setup for the $3^{1 / 8}$-in. and $61 / 8$-in. tests were identical except for the size of the coaxial lines. In both cases raw $\mathrm{rf}$ power was delivered from a klystron, tuned to $425 \mathrm{MHz}$, to a WR 1800 size waveguide. A waveguide-to-coax transition then delivered the power to the coaxial transmission line, window test module, and water load.

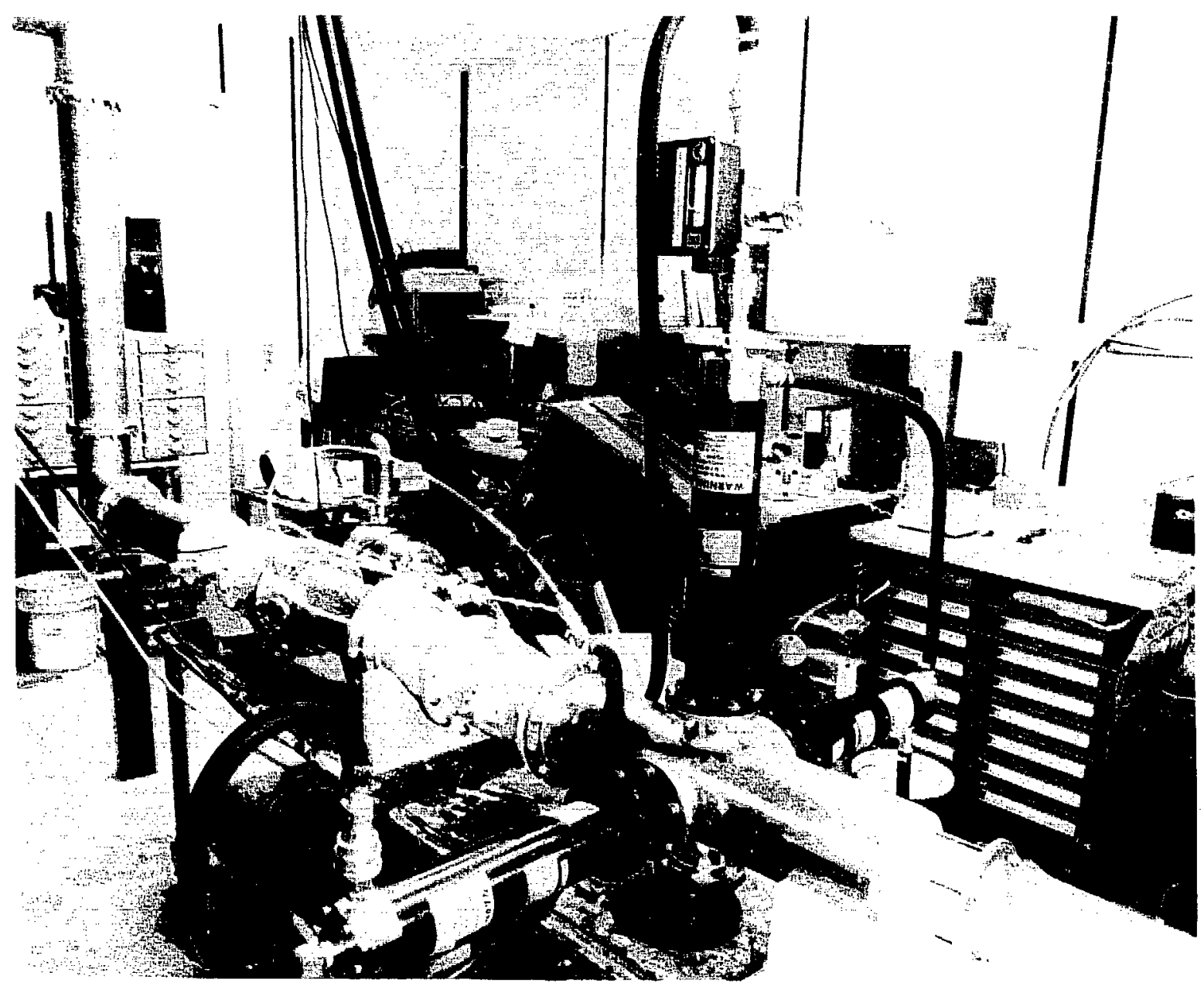

Fig. 5. Window test module experimental apparatus. 


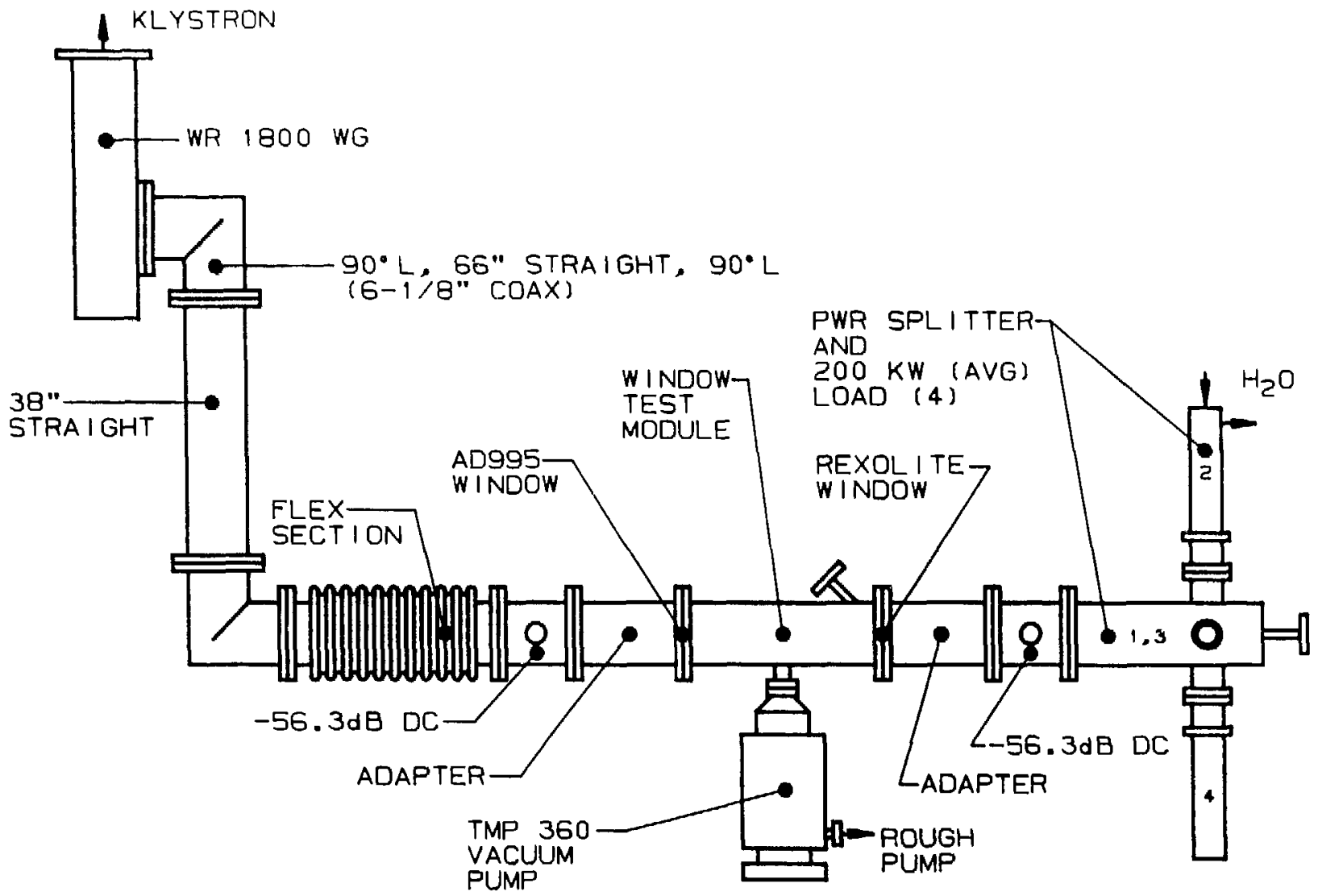

Fig. 6. The $6{ }^{1 / 8-i n}$. window test module experimental setup.

\section{B. Resonant Cavity Test Apparatus}

Tests of the drive loop and window assemblies can be done only into a cavity in which the loop is resonantly coupled. Such a setup is shown in Fig. 7 for the $61 / 8$-in. drive loop. The loop is designed with adjustable penetration and rotation so that a resonant match can be obtained. The flanges are equipped with $\mathrm{rf}$ and vacuum seals that can accommodate this adjustment. Once the match is made, the loop is bolted down, and primary vacuum is achieved by pumping on the cavity itself. Additional pumping is provided at the window itself by means of a small $8 \mathrm{l} / \mathrm{s}$ vacion appendage pump (Fig. 8) attached to the $6^{1 / 8}-\mathrm{in}$. unit. This appendage pump provides very little additional vacuum benefit, but gives a sensitive indication of multipactoring or sparking activity in the window region. This indication is very useful during conditioning as power is slowly increased. Use of the appendage pump is also shown in Fig. 9 attached to the $3^{1 / 8-i n}$. drive loop.

The rf cavities shown in Figs. 8 and 9 were both designed to resonate at $425 \mathrm{MHz}$. Both cavities are constructed of stainless steel in order to lower the $\mathbf{Q}$ to an unloaded value of $Q_{0}=9000$. This is done in order to simulate the relatively low $Q$ of a typical 


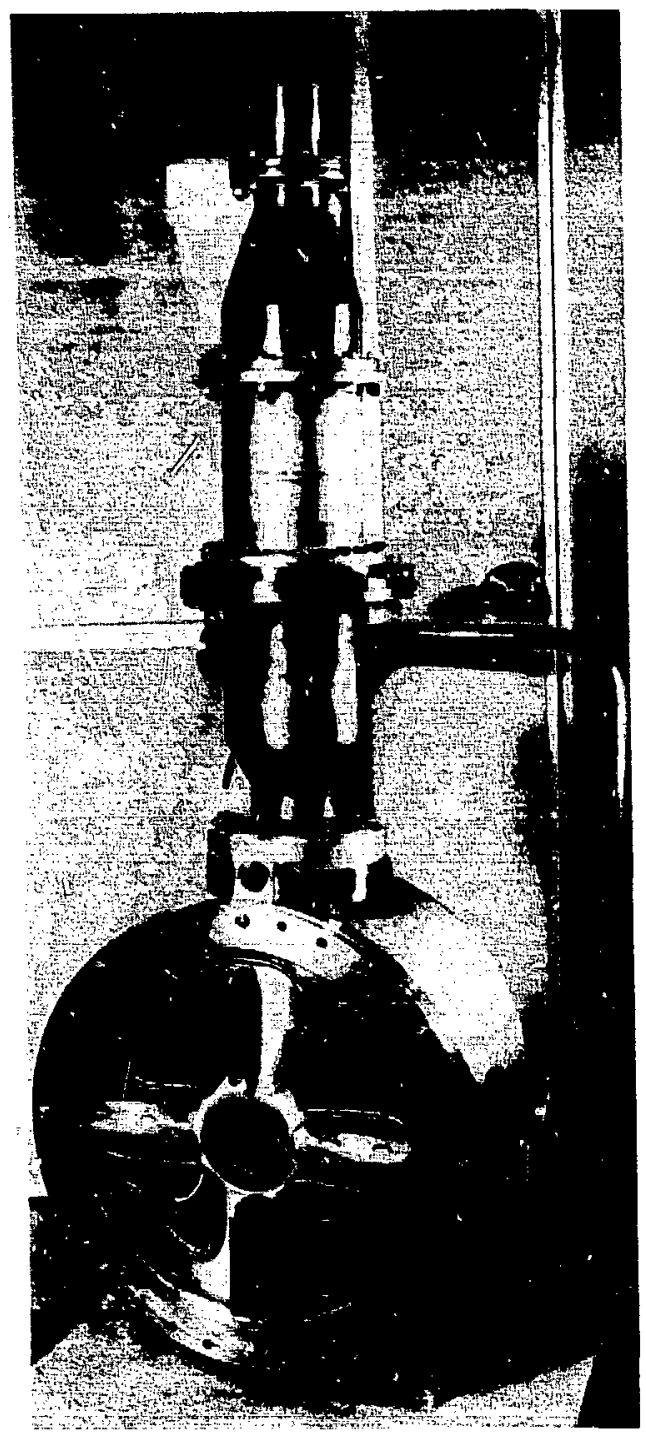

Fig. 7. The $61 / 8$-in. drive loop and adaptors mounted on a $425-\mathrm{MHz}$ water-cooied cavity.

425-MHz vane-type $R F Q\left(Q_{L} \sim 5500\right)$. Neither cavity had the power handling capacity to permit operation of the drive loops at their design rating of $5 \%$. Other factors such as capacitor bank limitations also limited power. However, all indications during testing showed the windows and loops capable of high duty factor operation and a logical continuation of the test program would be to locate a source of $\mathrm{rf}$ power capable of high duty or even continuous duty in this frequency range.

The experimental setup shown in Fig. 9 for the $3^{1 / 3-i n}$. drive loop includes a high capacity cryopump, which developed a very good cavity vacuum of $10^{-7}$ torr, and also a directional coupler in the drive line. The window unit shown attached to the drive loop is the ORNL module. 


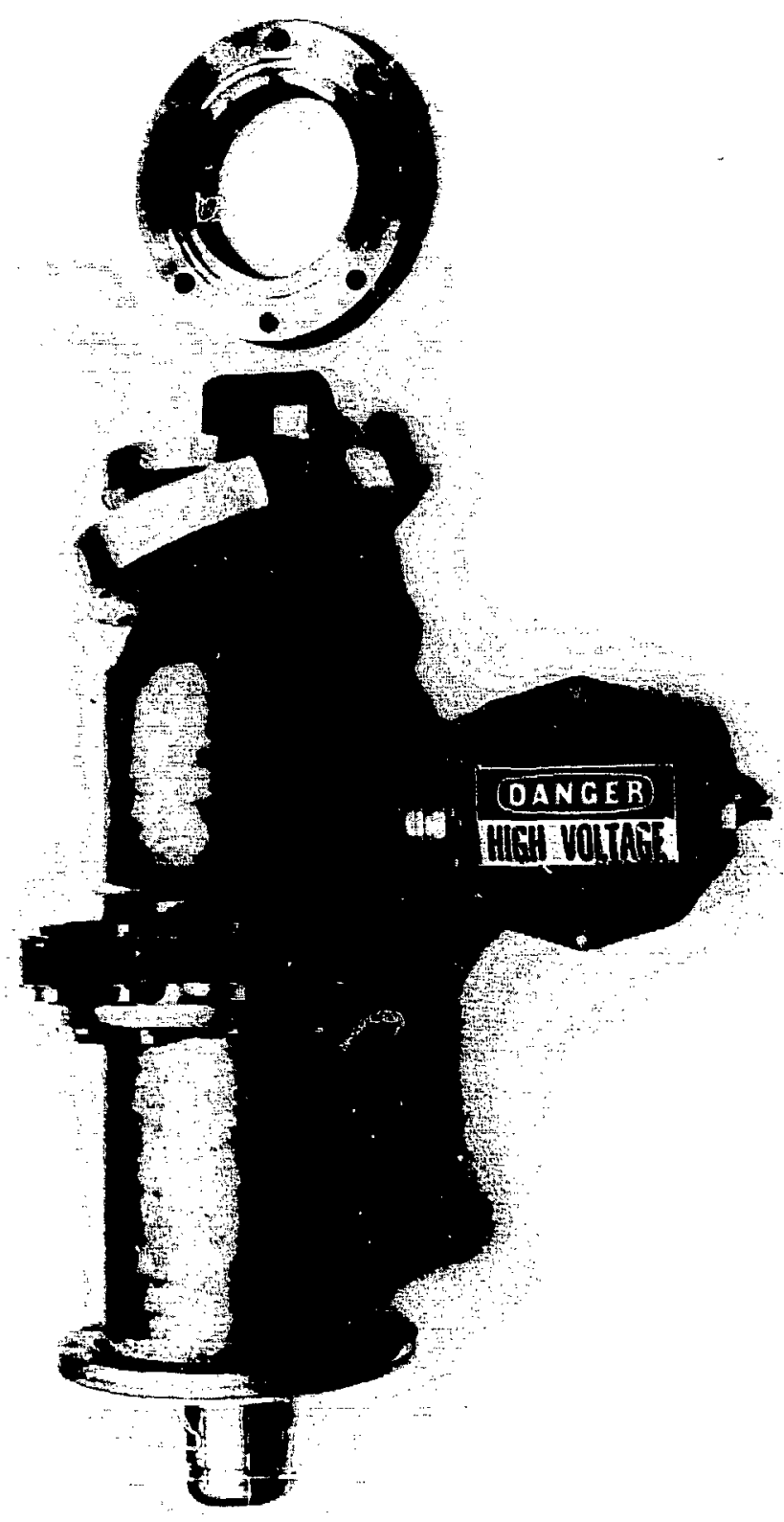

Fig. 8. The 61/8-in. drive loop with $8 \mathrm{P} / \mathrm{s}$ appendage pump, coupling flanges, and drive-line adaptor.

\section{TEST RESULTS}

Using the experimental setup described in Figs. 5 and 6, both size windows were tested. The results are given in Table I. Note that at $532 \mathrm{~kW}$, the $3^{1 / \mathrm{s}-i n}$. flat-disk window verged on sparking but the ORNL window did not. Even though both windows exceeded the original qualification test goal of $300 \mathrm{~kW}$ by over $75 \%$, the safety margin for the ORNL window was greater; this window was subsequently used in the resonant cavity tests. At high average power, our conclusion is that the $3^{1 / 8-i n}$. flat-disk window could operate at $5 \%$ duty if power was limited to the original design rating of $300 \mathrm{~kW}$. The ORNL window was not tested, although subsequent cavity tests indicate that it would be capable of high duty factor at $575 \mathrm{~kW}$. In the window tests, duty factor was limited to $3 \%$ because of the klystron capacitor bank ratings. 


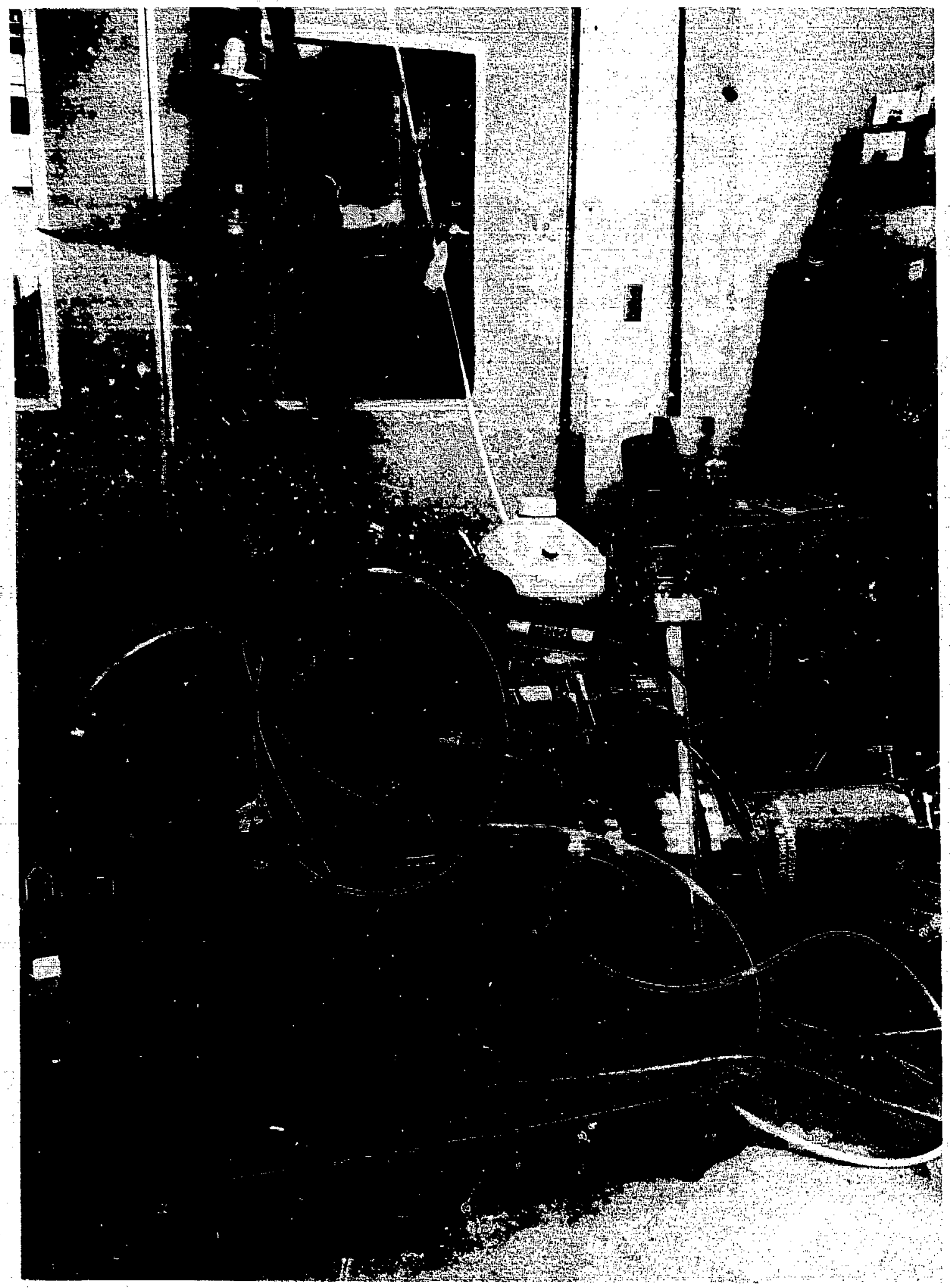

Fig. 9. The $3^{1 / 8-i n}$. drive loop and ORNL window under test into a stainless steel cavity. 
Table I

\begin{tabular}{|c|c|c|c|c|c|c|c|c|}
\hline \multirow{4}{*}{$\begin{array}{c}\text { Test } \\
\text { Parameters }\end{array}$} & \multirow{3}{*}{\multicolumn{2}{|c|}{$\begin{array}{c}\text { Qualification } \\
\text { Test } \\
\text { Goals }\end{array}$}} & \multicolumn{6}{|c|}{ Window Module Test Results } \\
\hline & & & \multicolumn{3}{|c|}{ High Peak Power } & \multicolumn{3}{|c|}{ High Avg. Power ${ }^{(3)}$} \\
\hline & & & \multicolumn{2}{|c|}{$31 / 8^{\prime \prime 1)}$} & \multirow{2}{*}{$61 / 8^{\prime \prime}$} & \multicolumn{2}{|c|}{$31 / 8^{\prime \prime(2)}$} & \multirow{2}{*}{$61 / 8^{\prime \prime}$} \\
\hline & $31 / 8^{\prime \prime}$ & $61 / 8^{\prime \prime}$ & LAINL & $\begin{array}{c}\text { SWAGED } \\
\lambda / 2\end{array}$ & & LANL & $\begin{array}{c}\text { SWAGED } \\
\lambda / 2\end{array}$ & \\
\hline Frequency, MHz & 425 & 425 & 425 & 425 & 425 & 425 & \multirow{5}{*}{$\begin{array}{l}\text { Not } \\
\text { Run }\end{array}$} & 425 \\
\hline Fwd Power, Kw & 300 & 850 & 532 & 532 & 1029 & 485 & & 965 \\
\hline Pulse Width, $\mu$ sec & 400 & 400 & 400 & 400 & 100 & 1000 & & 1000 \\
\hline Duty Factor, \% & $0.1 \mathrm{Min}$ & $0.1 \mathrm{Min}$ & 0.2 & 0.2 & 0.05 & 3.0 & & 3.0 \\
\hline VSWR $^{(4)}$ & 1.3 Max & 1.3 Max & 1.29 & 1.29 & 1.63 & 1.25 & & 1.66 \\
\hline
\end{tabular}

\section{Notes:}

(1) The LANL design verged on sparking under these conditions; the ORNL design did not.

(2) This was a $5 \mathrm{~min}$. run. Derating to $\mathrm{PFWD}=300 \mathrm{~kW}$ recommended for extended operation at duty factor $=5 \%$

(3) $3 \%$ duty factor is max. capacity of AT-2 klystron power system.

(4) The $61 / 8^{\prime \prime}$ window tests used a LANL built power splitter with VSWR $\sim 1.32$. Thus the high VSWR seen at the $6 \mathrm{1} / 8^{\prime \prime}$ window module also reflects this mismatch and is not due to the window module alone. 
Results achieved when operating into resonant cavities are listed in Table II. Here the duty factor was severely limited by cavity cooling, but long pulse lengths could be delivered to assure that all rf phenomena in the loop and window area were at

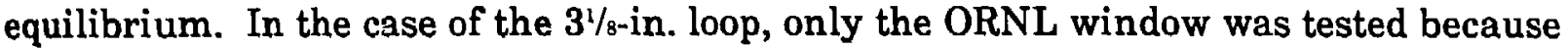
the window tests indicated that it was the unit of choice.

\section{Table II}

\begin{tabular}{|l|c|c||c|c|}
\hline \multirow{2}{*}{$\begin{array}{c}\text { Test } \\
\text { Parameters }\end{array}$} & \multicolumn{2}{c||}{$\begin{array}{c}\text { Qualification } \\
\text { Test } \\
\text { Goals }\end{array}$} & \multicolumn{2}{c|}{$\begin{array}{c}\text { Test Results } \\
\text { Into Resonant Cavity } \\
\text { (Q0 9000) }\end{array}$} \\
\cline { 2 - 5 } & $31 / 8^{\prime \prime}$ & $61 / 8^{\prime \prime}$ & $31 / 8^{\prime \prime}$ & $61 / 8^{\prime \prime}$ \\
\hline Frequency, MHz & 425 & 425 & 425 & 425 \\
\hline Fwd Power, Kw & 500 & 1000 & 575 & 1080 \\
\hline Pulse Width, $\mu \mathrm{sec}$ & 1000 & 1000 & 1000 & 130 \\
\hline Duty Factor, \% & $5 \mathrm{Min}$ & $5 \mathrm{Min}$ & $0.1^{(1)}$ & $0.065^{(1)}$ \\
\hline VSWR & $1.5 \mathrm{Max}$ & $1.5 \mathrm{Max}$ & 1.13 & $1.49^{(2)}$ \\
\hline
\end{tabular}

Notes:

(1) Test duty factors were limited by cavity cooling and not the drive loops or windows.

(2) High VSWR on $61 / 8^{\prime \prime}$ test due to overcoupling of loop into cavity. 
During the testing in either the window test modules or the resonant cavities, there was no sensible indication of heating of the window flanges, O-ring areas, or the body of the drive loop, even at the highest available duty factors. Every indication points to a capability to operate at much higher duty factor than could be tested with available rf sources. Although it was shown that the ORNL window was superior to the flat-disk ceramic in $3^{1 / 8} / \mathrm{in}$, size, both the rexolite and ceramic flat disks performed satisfactorily at the highest power levels and duty factors that could be delivered. Either of these windows will achieve $1 \mathrm{MW}$ at high duty but, because of greater durability, ceramic is recommended for the $6^{1 / 8-i n}$. drive loop.

\section{CONCLUSIONS}

We have succeeded in developing two high-power drive-loop and $\mathrm{rf}$ window combinations for generic accelerator applications at $425 \mathrm{MHz}$. The two sizes, $3^{1 / 8-i n}$. and 6 $1 / 8$-in., fit commercial coaxial power transmission lines; the qualified peak power ratings operating into $Q_{0}=9000 \mathrm{rf}$ cavity structures are $500 \mathrm{~kW}$ and $1 \mathrm{MW}$, respectively. The use of flat-disk windows is satisfactory; although, in the $3^{1 / 8-i n}$. size, these disks shall be configured into a half-wavelength module as developed at ORNL. Both rexolite and high-purity alumina work well in the $6 \frac{1}{8}$-in. size. For proper operation over a wide power range, the vacuum side of the drive loop and window must be properly titani $\lrcorner m$ treated or excessive multipactoring will occur. Test results at high average power have been limited by the available rf power source and resonant loads. However, we believe that very high duty factor, possibly $\mathrm{CW}$, might be achievable in these designs with relatively small changes.

\section{ACKNOWLEDGMENTS}

This program required help from many people to reach this successful conclusion. Rick Lohsen provided the drive lines, directional coupler, and the cavity, which was designed by Don Clark. Joe Uher helped build the high-duîy, water-cooled cavity. Bob Grieggs and Bob Cady did the titanium work on the loop and window. Gerry Bolme provided the laboratory space and, along with Cliff Fortgang and Carl Friedrichs, did a lot of the testing. Clark Bridgman assisted in procuring the vacuum system components. Glen Zimmerman helped hook up and modify the system as required. Don Reid, Jim Potter, George Spalek, and Gene Starke provided design input and code checks early in the design. And, of course, Dick Purser supported the program by providing the authorization to use Bolme's laboratory. Bob Patton, Ken Lyons, and Dick Graham ran the klystron for us. 


\section{APPENDIX TITANIUM COATING OF RF SURFACES}

\section{REASONS FOR TITANIUM COATING THE WINDOWS}

Early results from the $61 / 8$-in. window test module indicated several intermediate power levels at which multipactoring occurred. At maximum power ( $1 \mathrm{MW}$ ), the system performed quietly even at $3 \%$ duty factor We decided to have the vacuum sides of both the alumina and rexolite windows titanium sputtered as well as the half-wavelength center conductor that joins them. A titanium wire was hot sputtered onto exposed surfaces. Vacuum quality starts at $10^{-6}$ torr but degrades as sputtering proceeds. Slow oxidation due to residual air in the chamber takes place so the process is carried out rather quickly until the resistivity of a test sample in the chamber reaches $1 \mathrm{M} \Omega / \mathrm{sq}$. The outer conductor of the window test module was not treated.

The presence of the titanium significantly reduced the intensity of multipactoring and the resulting piessure pulses generated. Vacuum quality remained in the mid $10^{\cdot 6}$ to mid $10^{-7}$ torr range throughout the tests. Following an initial conditioning run to 900 $\mathrm{kW}$ with a 100 - $\mu$ s pulse width at 5 pps $(0.05 \%$ duty factor $)$, the module was run up to the full power at a $1-\mathrm{ms}$ pulse width and $30 \mathrm{pps}$ (3\% duty factor) over a period of a few minutes. Then pressure vs power data was taken to define the multipactoring regions. This was done both with an ion gauge and with a phototube that could detect faint ionization photons caused by the discharges.

\section{TEST RESULTS}

The signal intensity vs power data is plotted in Fig. A-1. Comparison with the run done without titanium shows very pronounced multipactoring regions before and significantly reduced gas discharge after sputtering the vacuum surfaces.

Duty factor affects the magnitude of the multipactoring-induced gas discharge as shown in Fig. A-2. At 3\% duty, a sharp peak exists at $200 \mathrm{~kW}$, which did not show up at low duty. Although the pressure pulse at $650 \mathrm{~kW}$ is still there, it is more subdued than at low duty We suspect that a violent cleanup process took place in working up through the power range at high duty; this reduced the discharge intensity at higher power.

In any event, the pressure pulses are well controlled by the titanium sputtering and do not appear to threaten successful operation of the windows at any power level within the 1-MW range or at any duty factor up to at least $3 \%$.

\section{MULTIPACTORING ANALYSIS}

The classical formula for the upper limit of multipactor power as a function of a flat-sided gap and frequency is as follows:

$$
P_{M P}=\frac{16 f^{4} D^{4} m_{e}^{2}{ }_{n}^{2}}{2 e^{2} Z_{o}}(M K S)
$$


COAXIAL RF WINDOW TEST CHAMBER VRCUUM

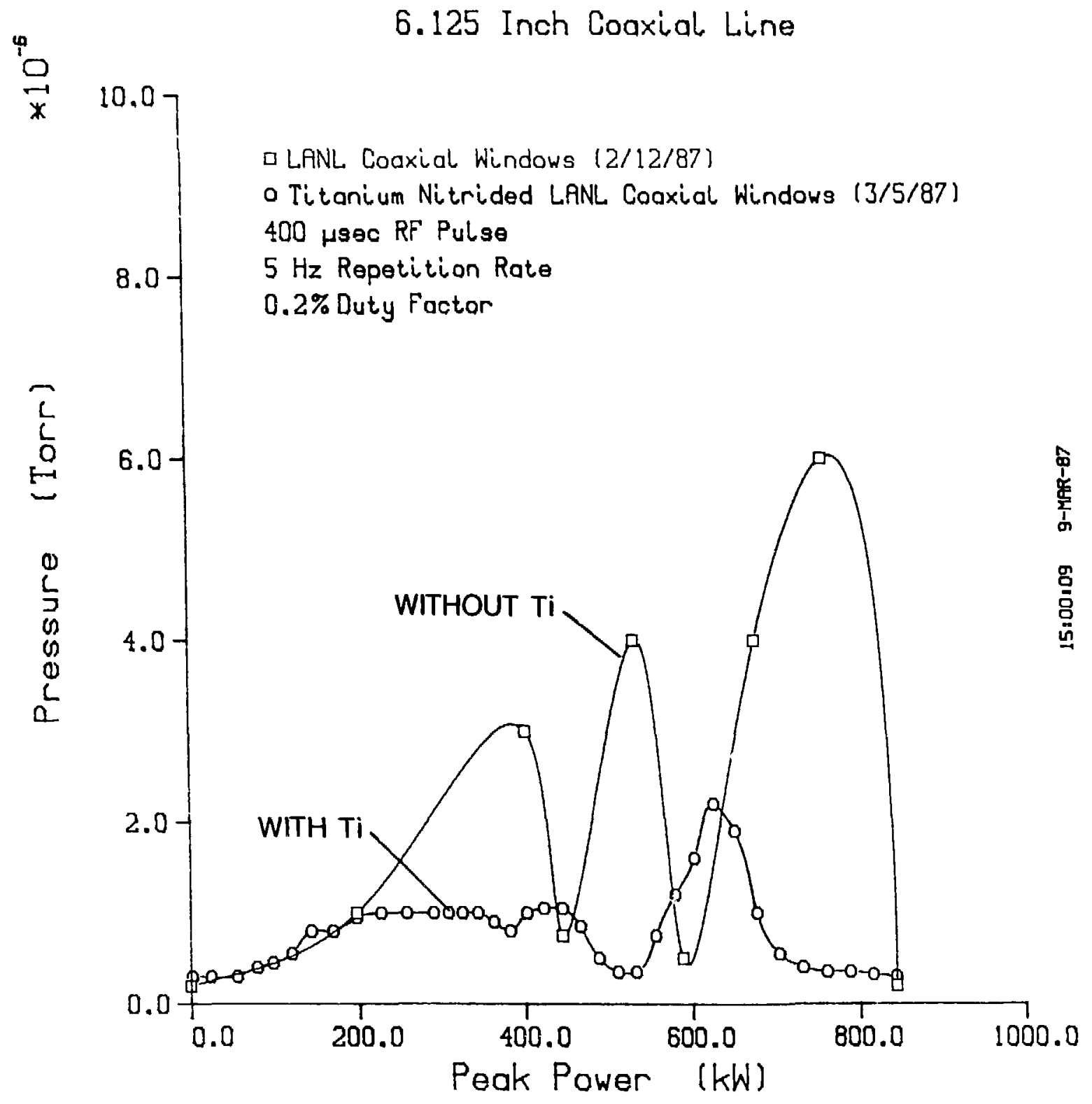

Fig. A-1. Reduction of multipactoring in the $6^{1 / 8-i n}$. window test module by means of titanium sputtering. 


\section{COAXIAL RF WINDOW TEST CHAMBER VACUUM}

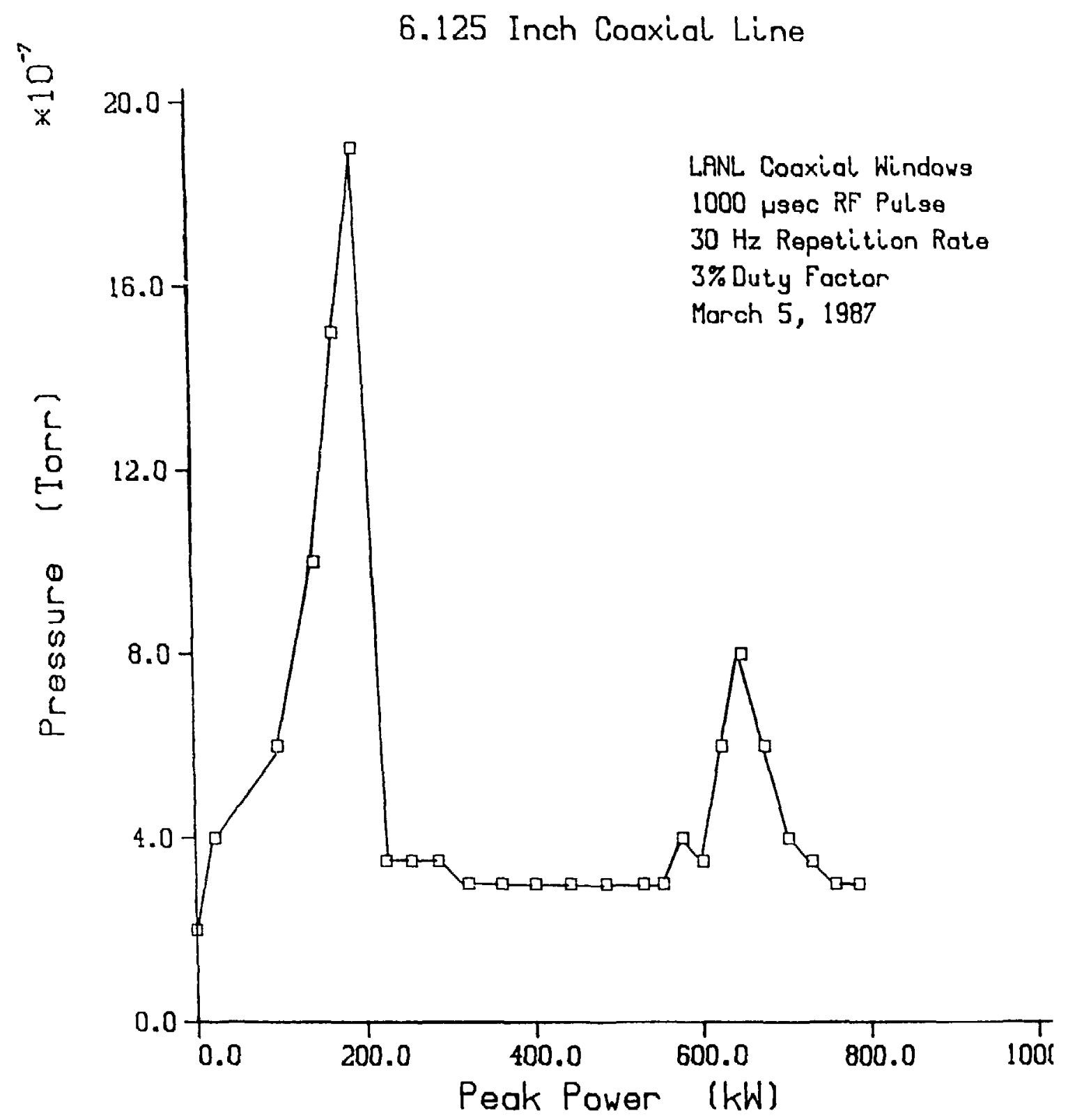

Fig. A-2. Multipactoring in the $6 \%$-in. window test module at high duty factor 
where $f=$ frequency

$$
\begin{aligned}
\mathbf{d} & =\text { gap } \\
\mathbf{m}_{\mathrm{e}} & =\text { electron mass } \\
\mathrm{e} & =\text { electron charge } \\
\mathrm{Z}_{0} & =\text { coaxial characteristic impedance }
\end{aligned}
$$

This formula can be written in terms of $(\mathrm{dBW})$ as follows:

$$
\begin{gathered}
P_{M P}(d B W)=10 \log _{10} P_{M P}=10 \log _{10}\left(\frac{8 m_{\varepsilon}^{2} \pi^{2}}{e^{2} Z_{0}} \times 10^{24}\right)+(10)(4) \log _{10}(f D) \\
P_{M P}(d B W)=17.08+40 \log _{10}(f D) \text { for } Z_{0}=50 \mathrm{ohms.}
\end{gathered}
$$

where $f=$ frequency in $\mathbf{G H z}$

$\mathrm{d}=$ gap in $\mathrm{mm}$

ORNL uses corollary equations that have proven valid in experiments with coaxial lines near $50 \Omega$ made of copper:

$$
\begin{gathered}
P_{\text {min }}(d B W)=6.5+20 \log _{10}(f D) \\
P_{\max }(d B W)=16.2+40 \log _{10}(f D)
\end{gathered}
$$

The above equations are plotted in Fig. A-3. The upper level of multipactoring agrees well with classical theory. The lower level is an experimental bound. Basically these equations say that multipactoring is possible in the entire range of operation for both the $6^{1 / 8-i n}$. and $3^{1 / 8-i n}$. coaxial lines. The particular pressure peaks shown in Figs. A-1 and A-2 are the result of electron traverses, which could be quite complex but in all cases fall within the range specified by the classical and ORNL equations. 


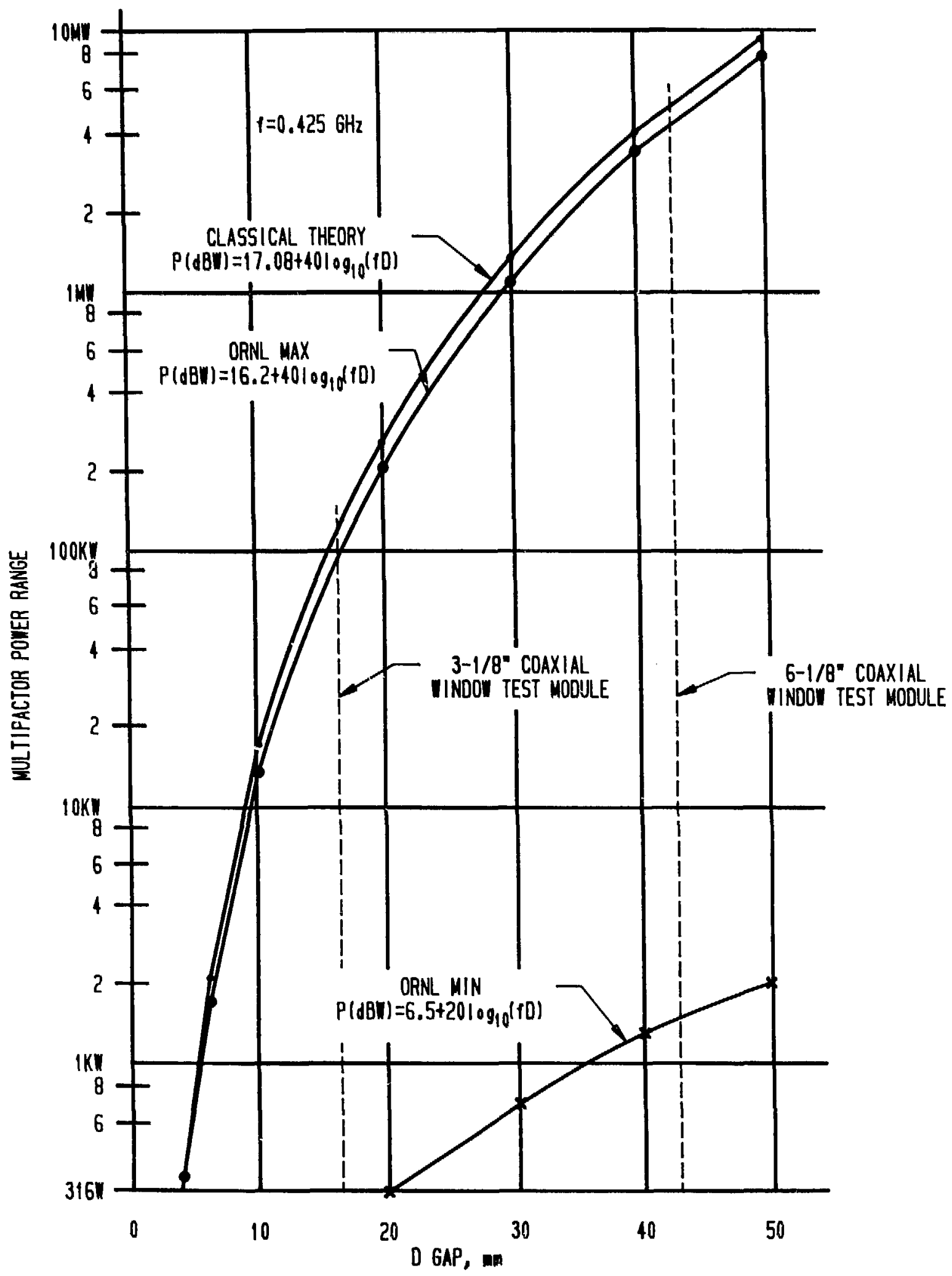

Fig. A-3. Multipactor power vs gap. 


\section{CONCULSIONS}

Because multipactoring is possible over the entire power range that the $61 / 8-i n$. and $3^{1 / 8-i n}$. drive loops operate over, it is necessary to treat the vacuum surfaces with titanium. The titanium-sputtering technique is for the ceramic surfaces on the vacuum side, and the titanium nitride technique described in Sec. I is used for the metallic surfaces on the vacuum side.

\section{REFERENCES}

1. Elimination of Mul'ipactoring in the FMIT RFQ Accelerator, W. Curnelius, R. Grieggs, LA-UR-84-2489. 